\title{
Atmospherically-promoted photosynthetic activity in a well-mixed ecosystem: Significance of wet deposition events of nitrogen compounds
}

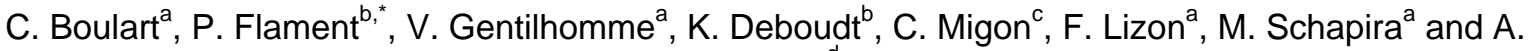 \\ Lefebvre $^{d}$
}

\author{
a'Station Marine de Wimereux, Université de Lille 1, FRE CNRS 2816 ELICO, 28 Avenue Foch, F- \\ 62930 Wimereux, France \\ ${ }^{\mathrm{b}}$ Maison de la Recherche en Environnement Naturel, Université du Littoral Côte d'Opale, FRE CNRS \\ 2816 ELICO, 32 Avenue Foch, F-62930 Wimereux, France \\ 'Laboratoire d'Océanographie de Villefranche, Université Paris 6, CNRS-INSU, La Darse, BP 8, F- \\ 06238 Villefranche-sur-Mer, France \\ dLaboratoire Environnement Littoral et Ressources Aquacoles, IFREMER, 150 Quai Gambetta, BP \\ 699, F-62321 Boulogne-sur-Mer, France
}

\footnotetext{
*: Corresponding author : Present address: National Oceanography Centre, School of Earth and Ocean Science, European Way, Southampton, SO14 3ZH, United Kingdom. Email : pascal.flament@univ-littoral.fr
}

\begin{abstract}
Wet atmospheric deposition of dissolved N, P and Si species is studied in well-mixed coastal ecosystem to evaluate its potential to stimulate photosynthetic activities in nutrient-depleted conditions. Our results show that, during spring, seawater is greatly depleted in major nutrients: Dissolved Inorganic Nitrogen (DIN), Dissolved Inorganic Phosphorus (DIP) and Silicic acid (Si), in parallel with an increase of phytoplanktonic biomass. In spring (March-May) and summer (JuneSeptember), wet atmospheric deposition is the predominant source $(>60 \%$, relative to riverine contribution) for nitrates and ammonium inputs to this $\mathrm{N}$-limited coastal ecosystem. During winter (October-February), riverine inputs of DIN predominate (>80\%) and are annually the most important source of DIP (>90\%). This situation allows us to calculate the possibility for a significant contribution to primary production in May 2003, from atmospheric deposition (total input for DIN $\approx 300 \mathrm{~kg} \mathrm{~km}^{-2}$ month $^{-1}$ ). Based on usual Redfield ratios and assuming that all of the atmosphericderived $N(A D-N)$ in rainwater is bioavailable for phytoplankton growth, we can estimate new production due to AD-N of $950 \mathrm{mg} \mathrm{C} \mathrm{m}^{-2}$ month $^{-1}$, during this period of depletion in the water column. During the same episode (May 2003), photosynthetic activity rate, considered as gross primary production, was estimated to approximately $30300 \mathrm{mg} \mathrm{C} \mathrm{m}^{-2} \mathrm{month}^{-1}$. Calculation indicates that new photosynthetic activity due to wet atmospheric inputs of nitrogen could be up to $3 \%$.
\end{abstract}

Keywords: primary production; coastal zone; atmospheric deposition; river plumes; nutrient cycles; Strait of Dover 


\section{Introduction}

Coastal seas represent one of the most valuable resources on the planet, but they are under strong anthropogenic pressure such as fisheries, industry or tourism. As a case study, the Eastern English Channel and the Southern Bight of the North Sea constitute an area under direct influence of anthropogenic nitrogen (N) sources (De Leeuw et al., 2003).

For many years, coastal ecosystems have been the subject of various studies on nutrient inputs as a possible cause for harmful algal blooms (e.g., Paerl, 1997; De Leeuw et al., 2001, 2002) and nuisance blooms of Phaeocystis globosa in Eastern English Channel waters (Gentilhomme and Lizon, 1998).

Nitrogen is generally viewed as the limiting factor for primary production (PP - Dugdale and Goering, 1967), especially in the North Sea basin (Kronvang et al., 1993; De Leeuw et al., 2003). The riverine supply of $\mathrm{N}$ to the sea has increased considerably in the last century (Paerl et al., 2000; Carstensen et al., 2005), but atmospheric inputs may constitute an important direct pathway for nutrients to the sea (Migon et al., 1989; Bergametti et al., 1992; Van Jaarsveld, 1995; De Leeuw et al., 2003), especially for open ocean environments (Owens et al., 1992; Galloway et al., 1993; Jickells, 1995). Atmospheric deposition of nitrogen compounds has been shown to be significant in coastal seas, especially in summer and fall when riverine inputs are low (Paerl et al., 2000; De Leeuw et al., 2002). For the total North

Sea, where there is a relatively high riverine input, direct atmospheric contribution to the total nitrogen load has been reported to be between 30 and 40\% (Rendell et al., 1993; De Leeuw et al., 2002). The atmospheric input is highly episodic with, generally, little seasonal variations compared with continental inputs (Michaels et al., 1993; Spokes et al., 1993).

Previous studies in the Eastern English Channel (Bentley et al., 1993; Laane et al., 1993; Brunet et al., 1996; Gentilhomme and Lizon, 1998) have shown typical seasonal cycle of nutrients and chlorophyll. In early spring, the rise of temperatures and the winter stock of 
1 nutrients in the water body lead to a phytoplankton bloom that generally ends in May or June.

2 This bloom is characterized by the succession of two groups of phytoplankton (Quisthoudt,

3 1987; Lancelot, 1989): diatoms and Prymnesiophycae such as Phaeocystis globosa. Some

4 recent observations in the Eastern English Channel and other coastal ecosystems, have shown

5 further phytoplankton blooms after late summer storms, suggesting an episodic direct

6 atmospheric input of nutrients and/or a substantial riverine input after runoff of rain waters

7 (Dupuy et al., 2000; D. Vincent - pers. comm.; M. Schapira - pers. comm.). The present study 8 aims:

- To quantify the direct atmospheric contribution to the $\mathrm{N}$ loading of coastal waters, by wet deposition,

- To estimate the significance of this input in comparison to riverine inputs, which integrate an indirect atmospheric contribution from land-based sources (Paerl et al., 2000), - And, in a case of clear $\mathrm{N}$ limitation, to determinate the gross primary production (GPP) rate supported by atmospheric input of nitrogen.

This study is not the first dealing with budget assessments of N-loading to estuaries and coastal water bodies (OSPAR, 2000; Valigura, 2000) and studies on the direct influence of atmospheric deposition on PP are not new (Paerl, 1985; Paerl and Whitall, 1999). This work represents one of the few studies on the effect of episodic impacts of AD-N on photosynthetic activity, in well-mixed water bodies.

\section{Study site and methods}

Eastern English Channel (Figure 1) is an epicontinental sea exhibiting high tidal flows with a transport of water masses from west to east (Pingree and Maddock, 1977). This results in an advection of Atlantic water masses to the North Sea, through the Strait of Dover. Near the French coasts, the structure is more complex due to the presence of rivers Seine, Somme, 
1 Authie and Canche. These rivers generate a coastal water mass which drifts along the shore,

2 named "Coastal Flow” (Brylinski et al., 1991), separated from the open sea by a tidally-

3 maintained frontal area (Brylinski and Lagadeuc, 1990). The inshore water mass is

4 characterised by a lower salinity (32-33 PSU - Dupont et al., 1991), when compared to the

5 oceanic offshore waters (35 PSU). This coastal structure, under the direct influence of

6 freshwaters, is used here to define a coastal box (CB), to calculate and compare atmospheric

7 and riverine inputs in the Strait of Dover area (see Fig. 1). This CB "Strait of Dover" is

8 geographically limited to $111 \mathrm{~km}^{2}$ in order to ensure spatial representative to our comparisons,

9 according to the location of the wet-only collector (Fig. 1). The western limit of the CB

corresponds to the mean position of the Coastal Front. Taking into account the bathymetry,

11 the volume of the water body is about $3 \mathrm{~km}^{3}$.

12 It is recognised that rainfall is two times less intense over the open sea than on the coast

13 (Elliott and Reed, 1973; Bethoux, 1977), but the number of rain events is more or less equal.

14 As indicated by Migon et al., 1991, the number of rain events has a greater influence on flux

15 than the intensity of the rain. This is confirmed in our survey in which, after long dry periods

16 (typically several days), $\mathrm{N}$ concentrations in rainwaters are systematically higher than

17 monthly mean concentrations, regardless the intensity of the rain event.

18 The Eastern English Channel is characterised by an oceanic temperate climate.

Predominant winds $(\approx 50 \%)$ are oriented south and west. This main direction corresponds to low pressure systems over the North Atlantic and leads to major rain events. Northeasterlies constitute the second main wind direction $(\approx 25 \%)$ and corresponds to anticyclonic situations and dry periods. On an annual basis, the mean wind speed is about $20 \mathrm{~km} . \mathrm{h}^{-1}$ (Flament et al., 1996). Annual precipitations range between 800 and $1000 \mathrm{~mm}$ (40 to $60 \mathrm{~mm}$ per month between February and August, and 70 to 90 mm from September to January). In spring 2003, 
1 precipitations were 20 to $60 \%$ lower than the seasonal mean (Meteo-France Data,

2 www.meteofrance.com/FR/climat/).

3 Two years of sea surveys (R.V. "Côtes de la Manche”, INSU/CNRS) were carried out in

4 Eastern English Channel in springs 2003 (March, April, May and June) and 2004 (March,

5 April and May). In each of the surveys, CTD hydrocasts (SBE 25 Sealogger CTD) were made

6 to determine temperature and salinity down the water column at several stations (Figure 1),

7 distributed regularly to give a good spatial representation. For each station, seawater was

8 collected at $1 \mathrm{~m}$ depth using a NISKIN ${ }^{\mathrm{TM}}$ bottle.

The Eastern English Channel is well known to show homogeneous physical and chemical structure, through the water column (Lagadeuc et al., 1997; Lizon and Lagadeuc, 1998). A small stratification can sometimes occur between coastal and offshore waters in neap tide conditions. The duration of this stratification is very short, since destratification occurs at low waters, due to high current speeds in the shallow waters.

After collection, an aliquot of the water sample was frozen $\left(-18^{\circ} \mathrm{C}\right)$ on board, for nutrient analysis immediately following the cruise. Ammonium concentrations were measured directly on board, according to the Koroleff method (1969). Between $250 \mathrm{~mL}$ and 1L of seawater were filtered through $47 \mathrm{~mm}$ WHATMAN ${ }^{\top M}$ GF/C filters for chlorophyll $a$, pigments and suspended particulate matter. Filters were frozen immediately after $\left(-18^{\circ} \mathrm{C}\right)$. Full details on the procedure are given in Gentilhomme and Lizon (1998). Riverine concentrations of DIN and DIP were measured at salinity 0 for Liane, Wimereux and Slack (See Fig. 1), using similar procedures for sampling and analysis.

Nutrients in seawater, rain and freshwater were photometrically analyzed by an “AutoAnalyzer Alliance Futura” spectrophotometer, using established methodologies 24 (Gentilhomme and Lizon, 1998). In total, samples were analyzed for Dissolved Inorganic 25 Nitrogen (DIN, representing the sum of $\mathrm{NO}_{3}{ }^{-}+\mathrm{NO}_{2}{ }^{-}+\mathrm{NH}_{4}{ }^{+}$), Dissolved Inorganic 
1 Phosphorus (DIP, representing $\mathrm{PO}_{4}{ }^{3-}$ ) and Si (dissolved silicate concentrations). Chlorophyll $a$

2 filters were extracted in $90 \%$ acetone in the dark for 4 hours. Concentration was determined

3 using a multi-wave length spectrophotometer and calculated according with Gentilhomme and

4 Lizon (1998). These data have been completed by data from the French Coastal Observation

5 Network SOMLIT from June 2003 to January 2004 (www.domino.u-

6 bordeaux.fr/somlit_national). These network data were acquired in the same experimental

7 conditions as this study, but samples were only taken off Wimereux.

Additionally, PP rate measurements were performed by twice daily sampling of seawater (5048’ $\left.\mathrm{N}, 1^{\circ} 34^{\prime} \mathrm{E}\right)$, each week during May 2003. Light intensity measurements were carried out off Wimereux, where the rainwater collector is located. PP rates were computed from

11 photosynthetic parameters, estimated with the ${ }^{14} \mathrm{C}$ technique and short incubation times

12 (Babin et al., 1994), and from light intensity measured each hour, during the studied month. This method approximates the carbon fixed by photosynthesis, called “Gross Primary Production" (GPP). The GPP is defined as the sum of the net primary production plus the autotrophic respiration. This photosynthetic activity was computed using averaged light extinction values and interpolated photosynthetic parameters to obtain daily GPP rates. Before summing daily GPP rates for the month of comparison, they were vertically integrated (through a 20-m depth water column). Full details on calculations are given in Lizon et al., 1995.

Rainwater was collected at Wimereux $\left(50^{\circ} 75^{\prime} \mathrm{N}-1^{\circ} 65^{\prime} \mathrm{E}\right)$, a semi-remote site located on the French coast of the Straits of Dover, from April 2003 to April 2004. The sampler is situated at the south of the town (8500 inhabitants), $50 \mathrm{~m}$ from the coastline and $10 \mathrm{~m}$ above sea level, relatively isolated and protected from local perturbations. Large agricultural fields and some buildings surround it. However, Wimereux is situated $10 \mathrm{~km}$ from Boulogne-surMer (in the South) and $30 \mathrm{~km}$ from Calais (in the North), medium-sized cities along French 
1 coast (100 000 inhabitants). Rainwater samples were collected on an event basis, using an

2 automatic homemade wet-only collector. This collector only opens when it rains and not

3 under the influence of the fog or dew. In addition, this device prevents from the

4 contamination by sea spray, containing nutrients recycled from the sea surface microlayer.

5 Rainwater is collected by a plastic funnel (area: $452 \mathrm{~cm}^{2}$ ), into pre-cleaned

6 FluoroEthylenePolymer (FEP) bottles. After the rain event, an automatic cleaning system of

7 the funnel is activated to rinse funnel and collecting network with ultrapure water $(\rho=18.2$

$8 \mathrm{M} \Omega . \mathrm{cm})$. A series of 8 bottles is placed on a carousel, which turns automatically every 24

9 hours.

Funnel and bottles are changed every week when it does not rain or after each rain event.

11 Sampling equipment was cleaned by soaking with $1 \mathrm{M}$ Nitric acid (Normapur ${ }^{\odot}$ grade) 2 to 3 days and then meticulously rinsed with ultra pure water. Funnel and bottles were soaked in 0.1M Nitric acid (Normapur ${ }^{\odot}$ grade), in ultrasonic bath for 1 hour, followed by 1 hour in 14 ultrasonic bath of ultrapure water and dried under a laminar flow hood (Class 100, U.S. 15 standard 209a).

To evaluate contamination, “field-blanks” were produced by simulating a rain event with ultrapure water $(125 \mathrm{~mL})$. Ultrapure water is then treated as a rain sample. Detection limits of this method are given in Table 1. 92 samples were collected between April 2003 and April 2004 (13 months). Rainwater was filtered through Nuclepore ${ }^{\mathrm{TM}}$ filters (diameter: $47 \mathrm{~mm}$, cutoff diameter: $0.45 \mu \mathrm{m}$, approximately the same as WHATMAN ${ }^{\mathrm{TM}} \mathrm{GF} / \mathrm{C}$ filters), under a

21 laminar flow hood. Nutrients concentrations have been determined for 76 events (82 \%).

22 Samples for ammonium were directly analyzed in glass bottle, whereas those for $\mathrm{NO}_{3}{ }^{-}, \mathrm{NO}_{2}{ }^{-}$,

23 DIP and Si measurements were frozen $\left(-18^{\circ} \mathrm{C}\right)$ in plastic tubes. Analytical methods were validated by analyzing certified rainwater (AES 02, NRC Canada). Results are given in

Figure 2. 


\section{3. Results}

\subsection{Hydrological environment}

Vertically averaged salinity did not exhibit any temporal pattern over the two surveys, but a rather stationary behaviour fluctuating between $33.1 \pm 0.4$ and $34.9 \pm 0.5$ in March 2003 and between $33.6 \pm 0.6$ (May) and $35.2 \pm 0.0$ (March) in 2004. In contrast, vertically averaged temperature exhibited a clear seasonal cycle throughout the two years, increasing gradually from $7.5 \pm 0.0^{\circ} \mathrm{C}$ to $18.7 \pm 0.2^{\circ} \mathrm{C}$ between March and June 2003 , and from $8.7 \pm 0.1^{\circ} \mathrm{C}$ to 11.5 $\pm 0.0^{\circ} \mathrm{C}$ between March and May 2004. These temperature and salinity values were fully consistent with previous measurements done at the seasonal scale in this area (Brunet et al., 1992; Brylinski et al., 1996; F. Lizon - pers. comm., Seuront et al., In Press). In addition, associated low standard deviation values $\left(<0.1\right.$ to $\left.0.6{ }^{\circ} \mathrm{C}\right)$ indicated that water column was well-mixed over the both studied periods, as previously shown in the whole studied area (Lizon et al., 1995; Gentilhomme and Lizon, 1998; Seuront and Schmitt, 1996; Seuront and Lagadeuc, 1998; Seuront et al., 1999, 2002, In Press).

3.2. Nutrients and chlorophyll a in seawater: measured concentrations and calculated stocks Arithmetic means and ranges of concentrations for DIN, DIP, Si and chlorophyll $a$ are summarised in Table 2. DIN concentrations measured here range between 5 and $52 \mu \mathrm{M}$ in March, followed by a fall to between 0.3 and $6.6 \mu \mathrm{M}$ in early spring (April and May). This behaviour is not seen for DIP. Chlorophyll $a$ concentrations show a decrease in spring 2003 (not in 2004). This decrease seems to be associated with the depletion of DIN and, to a lesser extent, Si. Stocks of DIN, DIP and Si for the CB area are presented in Figure 3. Nutrient stocks are calculated for each survey from the mean nutrient concentration. The DIN inventory ranged from around 1100 T. $\mathrm{km}^{-3}$ in winter to less than 33 T.km ${ }^{-3}$ in spring. DIP 
1 inventory ranged from $73 \mathrm{~T} . \mathrm{km}^{-3}$ in winter to around $10 \mathrm{~T} . \mathrm{km}^{-3}$ in summer. For Si, the

2 inventory ranged from 670 T.km ${ }^{-3}$ in winter, to less than $10 \mathrm{~T} . \mathrm{km}^{-3}$ in spring.

3

\subsection{Nutrient concentrations in rainwater and wet atmospheric inputs to the CB "Strait of} Dover”

Rainfall and nutrient concentrations in rainwater are given in Table 3. Percentages indicate the ratio of analyzed rain events. Clearly, major DIN species are nitrate and ammonium salts, nitrites are negligible in the DIN budget. The predominance of nitrates and ammonium salts in the DIN mass balance has been already established for other coastal ecosystems (Migon et al., 1989; Scudlark et al., 2005). For each rain event, the wet input of a nutrient ( $\mathrm{F}$ in $\mu \mathrm{mol} . \mathrm{m}^{-2}$ ) is calculated as:

$$
F=\frac{C \times V}{S}
$$

where $\mathrm{C}$ is the nutrient concentration $\left(\mu \mathrm{mol} . \mathrm{L}^{-1}\right)$ in the rain sample, $\mathrm{V}$ is the volume $(\mathrm{L})$ of the rainwater measured by a rain-gauge and $\mathrm{S}$ is the area of the funnel $\left(0.0452 \mathrm{~m}^{2}\right)$. Rainfalls less than $2 \mathrm{~mm}$ are not taken into account due to lack of sample. Wet inputs are cumulated for each month and are presented in Figure 4. Atmospheric deposition of DIN was estimated to be $\approx 415$ T for the CB, from April 2003 to April 2004. Seasonally, these inputs ranged approximately from 5 to $100 \mathrm{~T}$.month ${ }^{-1}$. DIP inputs to the CB were estimated to be $12 \mathrm{~T}$, from April 2003 to April 2004 and they ranged from 0.1 to about 6 T.month ${ }^{-1}$. Si inputs were estimated to be $10 \mathrm{~T}$ for the same period and ranged between 0.1 and 4 T.month ${ }^{-1}$.

\subsection{Riverine inputs}

Riverine nutrient fluxes entering the coastal zone are modified within estuaries (Jickells, 1998), due to trapping by particles, resuspension of both marine and freshwater sediments, as

well as estuarine PP. The quantification of these processes is still poorly known. Sanders et al. 
1 (1997) have assessed a net export of DIN and DIP, at the tidal limits of the Humber River of,

2 respectively, 96 and 15\%, relative to quantities entering the estuary. Loquet et al. (2000) have

3 shown, for the Somme River, that during winter (December to March) the net export of DIN

4 and DIP corresponded respectively to 89 and $85 \%$ of the continental inputs to the Somme

5 estuary. During the April to September period, inputs to coastal sea from the Somme estuary

6 were limited due to depletion by phytoplankton and microphytobenthos. In summer (June to

7 August), almost $100 \%$ of DIN of continental input sinks in the Somme estuary. Morris et al

8 (1995) show clearly that river-derived nutrients are conservatively exported to coastal sea in

9 winter and that nutrients are consumed into plume estuaries faster than they are supplied by the river/estuary system, in spring. In summary, estuaries could be considered as a source of nutrients in winter and a sink in spring and summer. To evaluate the net export of riverine DIN and DIP to the CB "Strait of Dover" (Figure 5), we have adopted the quantitative estimations available for the closest estuary, i.e. the Bay of Somme (Loquet et al., 2000). From April 2003 to April 2004, a retention factor of 15\% has been applied to DIP fluxes. According to the same author, retention of $10 \%$ was applied to DIN fluxes during winter and $90 \%$ during spring and summer.

\section{Discussion}

\subsection{Evolution of stocks and concentrations of nutrients and chlorophyll a}

There is evidence for seasonal cycles of nutrients and chlorophyll $a$, which is typical of temperate seas (OSPAR, 2000). These seasonal patterns of nutrient stocks and chlorophyll a concentrations have been already described in the Eastern English Channel (Bentley et al., 1993; Laane et al., 1993; Gentilhomme and Lizon, 1998). During the winter period, phytoplankton growth is limited by light and temperature (Gentilhomme and Lizon, 1998) and the stocks of DIN, DIP and Si increase. These winter stocks (Figure 3) are strongly and 
1 quickly depleted during spring (by a factor of 7 for DIP, 33 for DIN and 67 for Si), due to

2 phytoplankton growth. In addition, the corresponding increase of mean chlorophyll $a$

3 concentrations between spring 2003 and spring 2004 (Table 2) is consistent with previous

4 observations of Gentilhomme and Lizon (1998). These authors illustrate the consequence of

5 phytoplankton growth limitation, depending on nutrient availability, which is dependant on

6 water column dynamics, meteorological patterns and external inputs. Whereas the bloom and

7 its relationship with nutrient occur every years, the timing and strength of this event is very

8 variable (Tungaraza et al., 2003). In 2003, an important bloom of diatoms occurred from

9 March. In 2004, two successive different blooms occurred in early March and in May (Table

2 and Figure 3). It is generally accepted that there are two blooms in the North Sea and the

11 Eastern English Channel (Lancelot, 1989). Large diatoms dominate the first bloom, which

12 occurs in early spring, and the second is characterized by the Prymnesiophycae Phaeocystis

globosa. In summer, smaller diatoms are predominant but concentrations of chlorophyll $a$ are

relatively low (Quisthoudt, 1987). For 2003, the exceptional meteorological conditions

(Meteo-France Data), in spring (relatively high light and temperature) could have results in

both blooms occurring in a very short time (less than one month) and are not distinguished in our survey. Accordingly, as indicated by Figure 3, May 2003 is characterised by the lowest DIN stock recorded in this study. The same effect is observed for Si, but this nutrient is only limiting for diatoms. There are always measurable DIP concentrations in our study area, indicating that it is not limiting. From our study, the Eastern English Channel and the North

21 Sea are clearly limited by N, in agreement with previous results from the ANICE project (de 22 Leeuw et al., 2003). In our coastal area, we are clearly, in May 2003, in N-limiting conditions 23 for phytoplankton growth. 
The extreme variability of nutrients concentrations in rainwater is not surprising: many

2 studies have shown at least one order of magnitude between minimum and maximum values

3 for nutrient concentrations in rainwater (e.g. Beverland et al., 1998; Scudlark et al., 2005).

4 For atmospherically-derived nitrogen (AD-N), wet deposition rates are influenced by urban

5 and industrial activities (e.g. nitrate from $\mathrm{NO}_{\mathrm{x}}$ conversion). Agricultural activities and

6 chicken/pig farming, emitting ammonium from $\mathrm{NH}_{3}$ conversion, are mentioned in addition to

7 explain this variability (Paerl, 1997 ; Paerl et al., 2000). Maximum AD-N wet depositions are

8 encountered in April, May and October 2003 (from 60 to 100 T.month $^{-1}$; Fig.4). These three

9 months are not particularly wet, but correspond to rain events occurring after long dry periods

10 (typically several days). As indicated in Section 2, in this situation, $\mathrm{N}$ concentrations in

11 rainwaters are systematically higher than monthly mean concentrations. This highlights the

12 occurrence of wash-out processes and, indirectly, suggests the accumulation of nitrogen compounds in the low troposphere during long dry periods. During these episodes, typically anticyclonic, wind speeds are low and local winds oriented to the continental sector (the countryside around Boulogne sur Mer, Calais and the industrial zone of Dunkirk harbour).

This sector can be view as a source of nutrients for the atmosphere (Paerl et al., 2000), due to extensive agricultural and industrial activities. The Dunkirk harbour industrial area (about 80 $\mathrm{km}$ from the Strait of Dover, in the Northeast) emits each year more than $10^{4} \mathrm{~T}\left(\mathrm{NO}+\mathrm{NO}_{2}\right)$. we note that they correspond with the minimum stock of DIN in seawater (Figure 3). Approximately 60\% of AD-N deposition occurs within 3 months (April, May and October 2003). In May 2003, period corresponding to photosynthetic-activity measurements, the AD$\mathrm{N}$ wet input is approximately 66 Tons and may represent a significant contribution of “new” $\mathrm{N}$ for $\mathrm{PP}$, in this oligotrophic area (N-depleted waters), as has been proposed in other studies (Benitez-Nelson, 2000; de Leeuw et al., 2003; Cartensen et al., 2005; Bartoli et al., 2005). 
24.3 Comparison with riverine inputs

3 Comparison of atmospheric versus riverine nutrient contributions to the CB is presented in

4 Figure 6. Through the 13 months survey, riverine inputs are the most important source for

5 DIP (> 90\%), with the exception of the May to August 2003 period. In spring and summer,

6 wet deposition becomes the major source ( $\geq 60 \%)$ for DIN, except in April $2004(\approx 40 \%)$.

7 During winter, DIN riverine inputs predominate ( $>80 \%)$. This comparison is calculated from

8 our data, with the caveat that we take into account wet atmospheric deposition. It is calculated

9 that dry deposition represents 20 to $25 \%$ of wet deposition in the North Sea basin (De Leeuw

10 et al., 2002). Even though this dry deposition is not considered here, our measurements fall

11 into the range of ACDEP results (De Leeuw et al., 2003). This indicates that not considering

12 dry deposition does not preclude a rough comparison of our results with those from ACDEP.

13 The efficiency of wash-out after long dry periods and the related deposition may explain the

14 absence of discrepancy between this study and the more extensive ANICE Project, in the

15 evaluation of $\mathrm{N}$ deposition rates.

4.4. Estimation of primary production triggered by $A D-N$

An evaluation of new production theoretically triggered by an atmospheric event $\left(\mathrm{NP}_{\mathrm{atmo}}\right)$, can be calculated using Redfield ratios:

$$
\mathrm{NP}_{\mathrm{atmo}}=[X] \frac{C}{X} \times 12
$$

21 where $[X]$ is the nutrient atmospheric input, expressed in $\mu \mathrm{mol} \mathrm{m}^{-2}$, with $\mathrm{X}=\mathrm{N}$, $\mathrm{P}$ or $\mathrm{Si}$,

$22 \frac{C}{X}$ is the carbon / nutrient Redfield ratio (Redfield et al., 1963), and 12 is the molar mass of

23 carbon, expressed in $\mathrm{g} \mathrm{mol}^{-1}$. $\mathrm{NP}_{\text {atmo }}$ is viewed as the quantity of carbon available for

24 photosynthetic activity and, as such, can be compared to the activity calculated from 
1 photosynthetic parameters, into the water column (see section 2). Nutrients cannot accumulate

2 in depleted surface waters and are rapidly consumed immediately after their incorporation in

3 seawater (Migon et al., 1989). In case of stratified water masses, the atmospheric input of

4 nutrients is often evaluated by comparison with PP within a thin layer (Migon and Sandroni,

51999 ; Ridame and Guieu, 2002; Bartoli et al., 2005). In this work, AD-N contribution is

6 compared with photosynthetic activity measured for the entire water column, due to the

7 absence of stratification. In May 2003, DIN concentrations in seawater were very low (0.3 to

$8 \quad 0.6 \mu \mathrm{M})$ and wet atmospheric inputs were estimated to $12 \mathrm{mmol} \cdot \mathrm{m}^{-2}$. Based on Redfield ratios

9 and assuming that total DIN in rainwater is bioavailable for phytoplankton, we can estimate

10 the $\mathrm{NP}_{\text {atmo }}$ to be $79.5 \mathrm{mmolC} . \mathrm{m}^{-2}\left(950 \mathrm{mgC} . \mathrm{m}^{-2}\right)$. During the same period (May 2003), the

11 photosynthetic activity, considered as a GPP, can be estimated to $30300 \mathrm{mgC} . \mathrm{m}^{-2}$.

12 Consequently, the atmospherically-promoted photosynthetic activity could be equivalent to

$3.1 \%$ of the total monthly GPP of phytoplankton. Such a result is consistent with other

studies in the south of the North Sea, where De Leeuw et al. (2003) have shown that total atmospheric inputs of DIN could support $5.5 \%$ of the total primary production during summer. In the Western Mediterranean sea, Guerzoni et al. (1999) reported that new production triggered by rain source of nitrogen could be of 3 to $6 \%$ of the total annual primary production rates.

\section{Conclusion}

In this work, our goal was to quantify the direct atmospheric contribution to the $\mathrm{N}$ loading of coastal waters, to estimate the significance of this input by comparison with riverine inputs, which integrate an indirect $\mathrm{N}$ atmospheric contribution from land-based sources. In a case of clear $\mathrm{N}$ limitation of the PP, the capacity of wet atmospheric deposition to support GPP, viewed as an atmospherically-promoted photosynthetic activity, has been 
1 estimated. For the Strait of Dover area, the seasonal cycles of nutrients and chlorophyll $a$,

2 typical of temperate coastal seas, is established. During spring, seawater is strongly depleted

3 in major nutrients (DIN, DIP and Si), in parallel with an increase of chlorophyll $a$

4 concentrations. The atmospheric input of nutrients occurring during this period may be use for

5 new PP. These inputs are characterized by their highly episodic nature. $60 \%$ of AD-N

6 deposition occurs within 3 months and more than 80\% for DIP. Compared with riverine

7 nutrient inputs, atmospheric deposition becomes the predominant source ( $\geq 60 \%$ ) for DIN in

8 spring and summer. That leads to the conclusion that atmospheric deposition can have a

9 significant contribution to new production, particularly in late spring (April and May). Based

on Redfield ratios and assuming that entire nitrogen in rainwater is bioavailable for

11 phytoplankton, we can estimate the atmospherically-promoted photosynthetic activity

12 equivalent to $950 \mathrm{mgC} \cdot \mathrm{m}^{-2}$ during May 2003. During the same period, GPP rates (estimated

13 by photosynthetic parameters) of coastal waters can be estimated to $30300 \mathrm{mgC} . \mathrm{m}^{-2}$.

14 Consequently, the theoretical new production due to atmospheric inputs of $\mathrm{N}$ compounds

could represent about $3 \%$ of total PP of phytoplankton. Numerous studies have been concerned with long-term assessments and comprehensive budgets of N-loading to estuaries and coastal water bodies (e.g. Valigura, 2000). Because the atmospheric source is quantitatively important and capable of stimulating PP in coastal ecosystems, the emphasis has been put on meaningful airsheds assessment studies and on comparisons of direct and indirect (i.e. through watersheds and estuarine waters) atmospheric contributions. Studies on the direct influence of atmospheric deposition on PP are not new. However, this work represents one of the sparse studies on episodic impacts of AD-N on GPP, computed from In Situ photosynthetic parameters, during a period of demonstrated N depletion. 
2 This work was supported by the National Programme on Coastal Environment (PNEC)

3 “Chantier Manche Orientale - Sud Mer du Nord” and the Regional Programme (CPER)

4 “Phaeocystis bloom and consequences on coastal ecosystem”.

5 The authors would like to thank D. Menu and L. Brutier for the design and the construction of

6 the wet-only collector, X. Mériaux and V. Cornille for their contribution to sampling and

7 analysis of rainwater and their work at sea, E.Lecuyer and N. Degros for SOMLIT data, all

8 participants to sea-cruises and captains and crews of the R.V. "Côtes de la Manche”. The

9 authors would like to express their gratitude to Dr. Doug. P. Connelly for literary criticism of 10 the manuscript.

\section{References}

Babin, M., Morel, A., Gagnon, R.,1994. An incubator designed for extensive and sensitive measurements of phytoplankton photosynthetic parameters. Limnology and Oceanography 39, 694-702.

17 Bartoli, G., Migon, C., Losno, R., 2005. Atmospheric input of dissolved inorganic phosphorus and silicon to the coastal north-western Mediterranean Sea: fluxes, variability and possible impact on phytoplankton dynamics. Deep-Sea Research I 52, 2005-2016.

Benitez-Nelson, C., 2000. The biogeochemical cycling of phosphorus in marine systems.

$21 \quad$ Earth-Science Review 51, 109-135.

22 Bentley, D., R. Lafite, Morley, N.H., James, R., Staham, P.J. and Guary, J.C., 1993. Flux de nutriments entre la Manche et la Mer du Nord. Situation actuelle et évolution depuis dix ans.

Oceanologica Acta 16, 599-606. 
1 Bergametti, G., Remoudaki, E., Losno, R., Steiner, E., Chatenet, B. and Buat-Ménard, P.,

2 1992. Source, transport and deposition of atmospheric phosphorus over the northwestern

3 Mediterranean. Journal of Atmospheric Chemistry 14, 501-513.

4 Bethoux, J.P., 1977. Les apports des bilans en chaleur, en eau et en sel à la compréhension de

5 l'écosystème méditerranéen. Proc. $4^{\text {th }}$ Colloq. Study and Management of Marine Systems

6 Université Catholique de Louvain, Louvain la Neuve, Belgique, pp. 181-194.

7 Beverland, I.J., Crowther, J.M., Srinivas, M.S.N. and Heal, M.R., 1998. The influence of 8 meteorology and atmospheric transport patterns on the chemical composition of rainfall in 9 south-east England. Atmospheric Environment 32(6), 1039-1048.

Brunet, C., Brylinski J. M. and Frontier, S., 1992. Productivity, photosynthetic pigments and 11 hydrology in the coastal front of the Eastern English Channel, Journal of Plankton Research 14, 1541-1552.

Brunet, C., Brylinski, J.M., Bodineau, L., Thoumelin, G., Bentley, D. and Hilde, D., 1996. Estuarine, Coastal and Shelf Science 43, 469-483.

Brylinski, J. M. and Lagadeuc Y., 1990. L'interface eaux côtières / eaux du large dans le Pas de Calais (côte française): une zone frontale. Comptes Rendus de l'Académie des Sciences, 311 Série II, 535-540.

Brylinski, J.-M., Lagadeuc, Y., Gentilhomme, V., Dupont, J.-P., Lafite, R., Dupeuble, P.-A., Huault, M.-F., Auger, Y., Puskaric, E., Wartel, M. and Cabioch, L., 1991. Le "fleuve côtier": un phénomène hydrologique important en Manche orientale. Exemple du Pas-de-Calais. Oceanologica Acta Special Issue Nº1, 197-203.

Brylinski, J. M., Brunet C., Bentley, D., Thoumelin, G. and Hilde, D., 1996. Hydrography and phytoplankton biomass in the Eastern English Channel in spring 1992. Estuarine, Coastal and Shelf Science 43, 507-519. 
1 Cartensen, J., Frohn, L.M., Hasager, C.B., Gustafsson B.G., 2005. Summer algal blooms in a

2 coastal ecosystem: the role of atmospheric deposition versus entrainment fluxes. Estuarine,

3 Coastal and Shelf Science 62, 595-608.

4 De Leeuw, G., Cohen, L., Frohn,L.M., Geernaert, G., Hertel, O., Jensen, B., Jickells, T., 5 Klein, L., Kunz, G.J., Lund, S., Moerman, M., Müller, F., Pedersen, B., von Salzen, K., 6 Schlünzen, K.H., Schulz, M., Skjoth, C.A., Sorensen, L.L., Spokes, L., Tamm, S., Vignati E. 7 2001. Atmospheric input of nitrogen into the North Sea: ANICE project overview. 8 Continental Shelf Research 21, 2073-2094.

9 De Leeuw, G., Skjoth, A.C., Hertel, O., Jickells, T., Spokes, L., Vignati, E., Frohn, L.M., Frydendall, J., Schulz, M., Tamm, S., Sorensen, L.L. and Kunz, G.J., 2002. Deposition of 11 nitrogen into the North Sea. Atmospheric Environment 37, S145-S165.

12 De Leeuw, G., Spokes, L., Jickells, T.D., Skjoth, A.C., Hertel, O., Vignatic, E., Tamme, S., Schulze, M., Sorensen, L.L., Pedersen, B., Klein, L. and Schlunzen, K.H., 2003. Atmospheric nitrogen inputs into the North Sea: effect on productivity. Continental Shelf Research 23, 1743-1755.

Dugdale, R.C. and Goering, J.J., 1967. Uptake of new and regenerated forms of nitrogen in primary productivity. Limnology and Oceanography 12, 196-206.

Dupont J.P., Lafite R., Huault M.F., Lamboy M., Brylinski J.M., Guegueniat P., 1991. La dynamique des masses d'eau et matière en suspension en Manche Orientale. Oceanologica Acta 11, 177-186.

Dupuy, C., Vaquer, A., Lam-Hoai, T., Rougier, C., Mazouni, N., Lautier, J., Collos, Y., Le Gall, S., 2000. Feeding rate of the oyster Crassostrea gigas in a natural plankton community on the Mediterranean Thau Lagoon. Marine Ecology Progress Series 205, 171-184.

Pacific. Journal of Geophysical Research 78, 7087-7091. 
1 Flament, P., Bertho, M.L., Deboudt, K. and Puskaric, E., 1996. Changes in the lead content of

2 atmospheric aerosols above the Eastern Channel between 1982/83 and 1994. The Science of

3 the Total Environment 192, 193-206.

4 Galloway, J.N., Savoie, D.L., Keene, W.C. and Prospero, J.M., 1993. The temporal and 5 spatial variability of scavenging ratios for NSS sulfate, nitrate, methanesulfonate and sodium 6 in the atmosphere over the North Atlantic Ocean. Atmospheric Environment 27A, 235-250.

7 Gentilhomme, V. and F. Lizon, 1998. Seasonal cycle of nitrogen and phytoplankton biomass 8 in a well-mixed coastal system (Eastern English Channel). Hydrobiologia 361, 191-199.

9 Guerzoni, S., Chester, R., Dulac, F., Moulin, C., Herut, B., Loÿe-Pilot., M.D., Measures, C., Migon, C., Molinaroli, E., Rossini, P., Saydam, C., Soudine, A. and Ziveri, P., 1999. The role 11 of atmospheric deposition in the biogeochemistry of the Mediterranean Sea. Progress in 12 Oceanography 44, 147-190.

Jickells, T. D., 1995. Atmospheric inputs of metals and nutrients to the oceans: their magnitude and effects. Marine Chemistry 48, 199-214.

Jickells, T., 1998. Nutrient biogeochemistry of the coastal zone. Science 281, 217-222.

Koroleff, F., 1969. Direct Determination of Ammonia in Natural Waters as Indophenol Blue. International Council for the Exploration of the Sea. International Council for the Exploration of the Sea. C.M. 1969/C:9 Hydr. Comm.

Kronvang, B., Ærtebjerg, G., Grant, R., Kristensen, P., Hovmand, M., Kirkegaard, J., 1993. Nationwide monitoring of nutrients and their ecological effects: state of the Danish aquatic environment. Ambio 22, 176-187.

22 Laane, R.W.P.M., Groeneveld, G., De Vries, A., van Bennekom, J. and Sydow, S., 1993. 23 Nutrients (N, P, Si) in the Channel and the Dover Strait: seasonal and year-to-year variation 24 and fluxes to the North Sea. Oceanologica Acta 16, 607-616. 
1 Lagadeuc, Y., Brylinski, J.M., Aelbrecht, D., 1997. Temporal variability of the vertical

2 stratification of a front in a tidal region of freshwater influence (ROFI) system. Journal of

3 Marine Research 12, 147-155.

4 Lancelot, C., 1989. Phaeocystis blooms in the continental coastal area of the Channel and the

5 North Sea. In: Lancelot C., Billen G. and Barth H., (Eds.), Water Pollution Research Report $6 \quad n^{\circ} 12$. CEC Publications, Brussels, Belgium.

7 Lizon F, Lagadeuc Y, Brunet C, Aelbrecht D, Bentley D., 1995. Primary production and 8 photoadaptation of phytoplankton in relation with tidal mixing in coastal waters. Journal of $9 \quad$ Plankton Research 17, 1039-1055.

Lizon, F. and Lagadeuc Y., 1998. Comparisons of primary production values estimated from 11 different incubation times in a coastal sea, Journal of Plankton Research, 20, 371-381

12 Loquet, N., Rybarczyck, H. and Elkaim, B., 2000. Echanges de sels nutritifs entre la zone 13 côtière et un système estuarien intertidal: la Baie de Somme (Manche, France). Oceanologica 14 Acta 23, 47-64.

Michaels, A.F., Siegel, D.A., Johnson, R.J., Knap, A.H., Galloway, J.N., 1993. Episodic inputs of atmospheric nitrogen to the Sargasso Sea: contributions to new production and phytoplankton blooms. Global Biogeochemical Cycles 7, 339-351.

Migon, C., Copin-Montégut, G., Elégant, L. and Morelli, J., 1989. Etude de l'apport atmosphérique en sels nutritifs au milieu côtier méditerranéen et implications biogéochimiques, Oceanologica Acta, 12, 187-191.

21 Migon, C., Morelli, J., Nicolas, E., Copin-Montegut, G., 1991. Evaluation of total 22 atmospheric deposition of $\mathrm{Pb}, \mathrm{Cd}, \mathrm{Cu}$ and $\mathrm{Zn}$ to the Ligurian Sea. The Science of the Total 23 Environment 105, 135-148.

24 Migon, C. and Sandroni, V., 1999. Phosphorus in rainwater: partitioning, inputs and impact 25 on the surface coastal ocean. Limnology and Oceanography 44, 1160-1165. 
1 Morris, A.W., Allen J.I., Howland R. J. M. and Wood R. G., 1995. The estuary plume zone:

2 source or sink for land-derived nutrient discharges? Estuarine, Coastal and Shelf Science 40, $3 \quad 387-402$.

4 OSPAR, 2000. Bilan de Santé 2000, Technical Report, Commission OSPAR, Londres, 108 + $5 \quad$ vii pp.

6 Owens, N.J.P., Galloway, N.J., Duce, R.A., 1992. Episodic atmospheric nitrogen deposition 7 to oligotrophic oceans. Nature 357, 397-399.

8 Paerl, H.W., 1985. Enhancement of marine primary production by nitrogen-enriched acid 9 rain. Nature 316, 747-749.

Paerl, H.W., 1997. Coastal eutrophication and harmful algal blooms: Importance of 11 atmospheric deposition and groundwater as "new" nitrogen and other nutrient sources. Limnology and Oceanography 42, 1154-1165.

13 Paerl, H.W., Whitall, D.R., 1999. Anthropogenically-derived atmospheric nitrogen 14 deposition, marine eutrophication and harmful algal bloom expansion: is there a link? Ambio 28, 307-311.

Paerl, H.W., Boynton, W.R., Dennis, R.L., Driscoll, C.T., Greening, H.S., Kremer, J.N., 17 Rabalais, N.N., Seitzinger, S.P., 2000. Atmospheric deposition of nitrogen in coastal waters: 18 biogeochemical and ecological implications. In: Valigura, R.A. (Editor.), Nitrogen Loading in Coastal Water Bodies: An Atmospheric Perspective, Coastal and Estuarine Studies, vol 57, AGU Press, Washington, DC, pp. 11-52.

Pingree, R. D. and L. Maddock, 1977. Tidal residual in the English Channel. Journal of the Marine Biological Association of the UK 55, 975-992.

23 Quisthoudt, C., 1987. Production primaire phytoplanctonique dans le détroit du Pas de Calais 24 (France): variations spatiales et annuelles au large du Cap Gris Nez. Comptes-rendus de 25 l’Académie des Sciences, Paris, Série III 304, 245-250. 
1 Redfield, A.C., Ketchum, B., and Richards, F., 1963. The influence of organisms on the

2 composition of sea water. In: Hill, N. (Ed.), The Sea, Vol. 2. Interscience, New York City, 3 NY, pp. 224-228.

4 Rendell, A.R., Ottley, C.J., Jickells, T.D., Harrison, R.M., 1993. The atmospheric input of 5 nitrogen species to the North Sea. Tellus 45B, 53-63.

6 Ridame, C. and Guieu, C., 2002. Saharan Input of Phosphate to the oligotrophic water of the 7 open western Mediterranean Sea. Limnology and Oceanography 47, 856-859.

8 Sanders, R.J., Jickells, T., Malcolm, S., Brown, J., Kirkwood, D., Reeve, A., Taylor, J., 9 Horrobin, T., Ashcroft, C., 1997. Nutrient fluxes through the Humber estuary. Journal of Sea Research 37, 3-23.

11 Seuront, L. and Schmitt F., 1996. Multifractal intermittency of Eulerian and Lagrangian 12 turbulence of ocean temperature and plankton fields. Nonlinear Processes in Geophysics 3, 236-246.

Seuront, L. and Lagadeuc, Y., 1998. Spatio-temporal structure of tidally mixed coastal waters: variability and heterogeneity. Journal of Plankton Research 20, 1387-1401.

Seuront, L., Schmitt, F., Lagadeuc, Y., Shertzer, D., and Lovejoy, S., 1999. Multifractal analysis as a tool to characterize multiscale inhomogeneous patterns. Example of phytoplankton distribution in turbulent coastal waters. Journal of Plankton Research 21, 877922.

Seuront, L., Gentilhomme V., and Lagadeuc, Y., 2002. Small-scale nutrient patches in tidally mixed coastal waters. Marine Ecology Progress Series 232, 29-44.

Seuront, L., Vincent D. and Mitchell, J.G. Biologicaly-inducted modification of seawater viscosity in the Eastern English Channel during a Phaeocystis globosa spring bloom. Journal of Marine Systems, in press. 
1 Scudlark, J.R., Jennings, J.A., Roadman, M.J., Savidge, K.B., Ullman, W.J., 2005.

2 Atmospheric nitrogen inputs to the Delaware Inland Bays: the role of ammonia.

3 Environmental Pollution 135 433-443

4 Spokes, L., Jickells, T., Rendell, A., Schulz, M., Rebers, A., Dannecker, W., Kruger, O.,

5 Leermakers, M., Baeyens, W., 1993. High atmospheric nitrogen deposition events over the

6 North Sea. Marine Pollution Bulletin 26, 698-703.

7 Tungaraza, C., Rousseau V., Brion, N., Lancelot, C., Gichuki, J. Baeyens, W., Goeyens, L.,

8 2003. Contrasting nitrogen up-take by diatom and Phaeocystis-dominated phytoplankton

9 assemblages in the North Sea. Journal of Experimental Marine Biology and Ecology 29, 191041.

11 Valigura, R.A., 2000. An Introduction to the First Assessment of Nitrogen Loads to US

12 Estuaries with an Atmospheric Perspective. In: Valigura, R.A. (Editor.), Nitrogen Loading in

13 Coastal Water Bodies: An Atmospheric Perspective, Coastal and Estuarine Studies, vol 57,

14 AGU Press, Washington, DC, pp. 1-10.

15 Van Jaarsveld, J.A., 1995. Atmospheric inputs to the North Sea and coastal waters. Journal of 16 the Institute for Weather Evaluation and Modelling, 7, 24-31. 
2 Figures Captions:

$5 \quad$ Figure 1: Study Site. Solid lines delimit the coastal box (CB) for stock calculations and

6 comparison of atmospheric versus riverine inputs. Adapted from Seuront et al., 2002.

7

8 Figure 2: Precision and accuracy of the rainwater sampling and analysis method (all results in $9 \quad \mu \mathrm{M})$.

Figure 3: Evolution of DIN, DIP and Si concentrations for the CB “Strait of Dover”, from 12 March 2003 to March $2004\left({\left.\mathrm{~T} . \mathrm{km}^{-3}\right) .}^{-3}\right.$

Figure 4: Evolution of wet atmospheric inputs of nutrients to the CB “Strait of Dover”, from April 2003 to April 2004 (Tons.month ${ }^{-1}$ ).

Figure 5: Net export of riverine nutrients to the CB "Strait of Dover" for DIN [a] and DIP [b], from April 2003 to April 2004 (Tons.month $^{-1}$ ).

19

Figure 6: Comparison of nutrients inputs to the CB "Strait of Dover" for DIN [a] and DIP 
Table 1: Detection limits of the rainwater sampling and analysis method (Detection limits corresponds to 3 time the standard deviation)

\begin{tabular}{cc}
\hline Nutrients & $\begin{array}{c}\text { Detection limits } \\
(\mu \mathrm{M})\end{array}$ \\
\hline $\mathrm{NO}_{3}{ }^{-}$ & 4.4 \\
$\mathrm{NO}_{2}{ }^{+}$ & 0.1 \\
$\mathrm{NH}_{4}{ }^{-}$ & 7.1 \\
$\mathrm{PO}_{4}{ }^{3-}$ & 0.4 \\
$\mathrm{Si}(\mathrm{OH})_{4}$ & 0.4 \\
\hline
\end{tabular}


Table 2: Arithmetic means $\left(\mu_{\mathrm{A}}\right)$ and ranges of DIN, DIP, Si, chlorophyll $a$ concentrations and temperatures, during sea-cruises. LD for Detection Limit

\begin{tabular}{ccccccccccc}
\hline \multirow{2}{*}{ Date } & \multicolumn{2}{c}{$\mathrm{DIN}(\mu \mathrm{M})$} & \multicolumn{2}{c}{$\mathrm{DIP}(\mu \mathrm{M})$} & \multicolumn{2}{c}{$\mathrm{Si}(\mu \mathrm{M})$} & \multicolumn{2}{c}{ Chlle $a\left(\mu \mathrm{g} . \mathrm{L}^{-1}\right)$} & \multicolumn{2}{c}{$\mathrm{T}\left({ }^{\circ} \mathrm{C}\right)$} \\
& $\mu_{\mathrm{A}}$ & range & $\mu_{\mathrm{A}}$ & range & $\mu_{\mathrm{A}}$ & range & $\mu_{\mathrm{A}}$ & range & $\mu_{\mathrm{A}}$ & range \\
\hline march-03 & 13.2 & $0.8-52.1$ & 0.4 & $0.3-0.8$ & 1.6 & $0.8-5.2$ & 35.2 & $2.1-96.4$ & 7.6 & $7.1-7.8$ \\
april-03 & 0.6 & $0.1-1.9$ & 0.2 & $0-4.2$ & 0.5 & $0-3.1$ & 11.2 & $2.4-53.5$ & 9.9 & $9.1-11.3$ \\
may-03 & 0.3 & $0.1-0.6$ & 0.2 & $0.05-0.7$ & 0.01 & $<\mathrm{LD}-0.07$ & 3.1 & $<\mathrm{LD}-17.4$ & 11.8 & $10.8-13.3$ \\
june-03 & 2.2 & $0.1-18.9$ & 0.3 & $0.1-3.7$ & 1.0 & $0.07-2.4$ & 5.2 & $<\mathrm{LD}-25.7$ & 16.8 & $15.3-19.0$ \\
march-04 & 9.7 & $4.8-15.9$ & 0.25 & $0.1-0.3$ & 2.2 & $0.1-3.1$ & 9.8 & $5.2-12.7$ & 7.1 & $6.8-7.3$ \\
april-04 & 2.6 & $0.7-6.6$ & 0.2 & $0.1-0.5$ & 1.4 & $0.8-6.3$ & 7.6 & $1.4-13.9$ & 9.0 & $8.7-9.3$ \\
may-04 & 1.2 & $0.5-2.2$ & 0.2 & $0.05-0.8$ & 1.2 & $0.8-1.8$ & 15.5 & $1.6-33.3$ & 11.1 & $10.7-11.8$ \\
\hline
\end{tabular}


Table 3: Pluviometry (mm) and mean concentrations of nutrients in rainwater, measured at Wimereux (See Fig. 1), from April 2003 to April 2004. $\mu_{\mathrm{A}}$ and $\mu_{\mathrm{G}}$ are respectively the arithmetic and geometric means, SD the standard deviation. LD for Detection Limit.

\begin{tabular}{ccccccc}
\hline & $\mathrm{mm}$ & $\begin{array}{c}\mathrm{DIP} \\
(\mu \mathrm{M})\end{array}$ & $\begin{array}{c}\mathrm{Si} \\
(\mu \mathrm{M})\end{array}$ & $\begin{array}{c}\mathrm{NO}_{2}{ }^{-} \\
(\mu \mathrm{M})\end{array}$ & $\begin{array}{c}\mathrm{NO}_{3}{ }^{-} \\
(\mathrm{mM})\end{array}$ & $\begin{array}{c}\mathrm{NH}_{4}{ }^{+} \\
(\mu \mathrm{M})\end{array}$ \\
\hline $\mathbf{\%}$ & 100 & 82 & 82 & 82 & 82 & 66 \\
$\mathbf{\mu}_{\mathbf{A}}$ & 5.1 & 3.5 & 3.5 & 0.8 & 0.14 & 85 \\
$\mathbf{\mu}_{\mathbf{G}}$ & 2.9 & 0.65 & 0.67 & 0.3 & 0.05 & 52 \\
$\mathbf{S D}$ & 5.9 & 10.4 & 14.6 & 1.8 & 0.41 & 77 \\
Median & 2.6 & 0.4 & 0.5 & 0.2 & 0.04 & 58 \\
$\mathbf{M a x}$ & 32 & 59 & 117 & 9.8 & 3.3 & 346 \\
Min & 0.3 & $<\mathrm{LD}$ & $<\mathrm{LD}$ & $<\mathrm{LD}$ & $<\mathrm{LD}$ & $<\mathrm{LD}$ \\
\hline
\end{tabular}




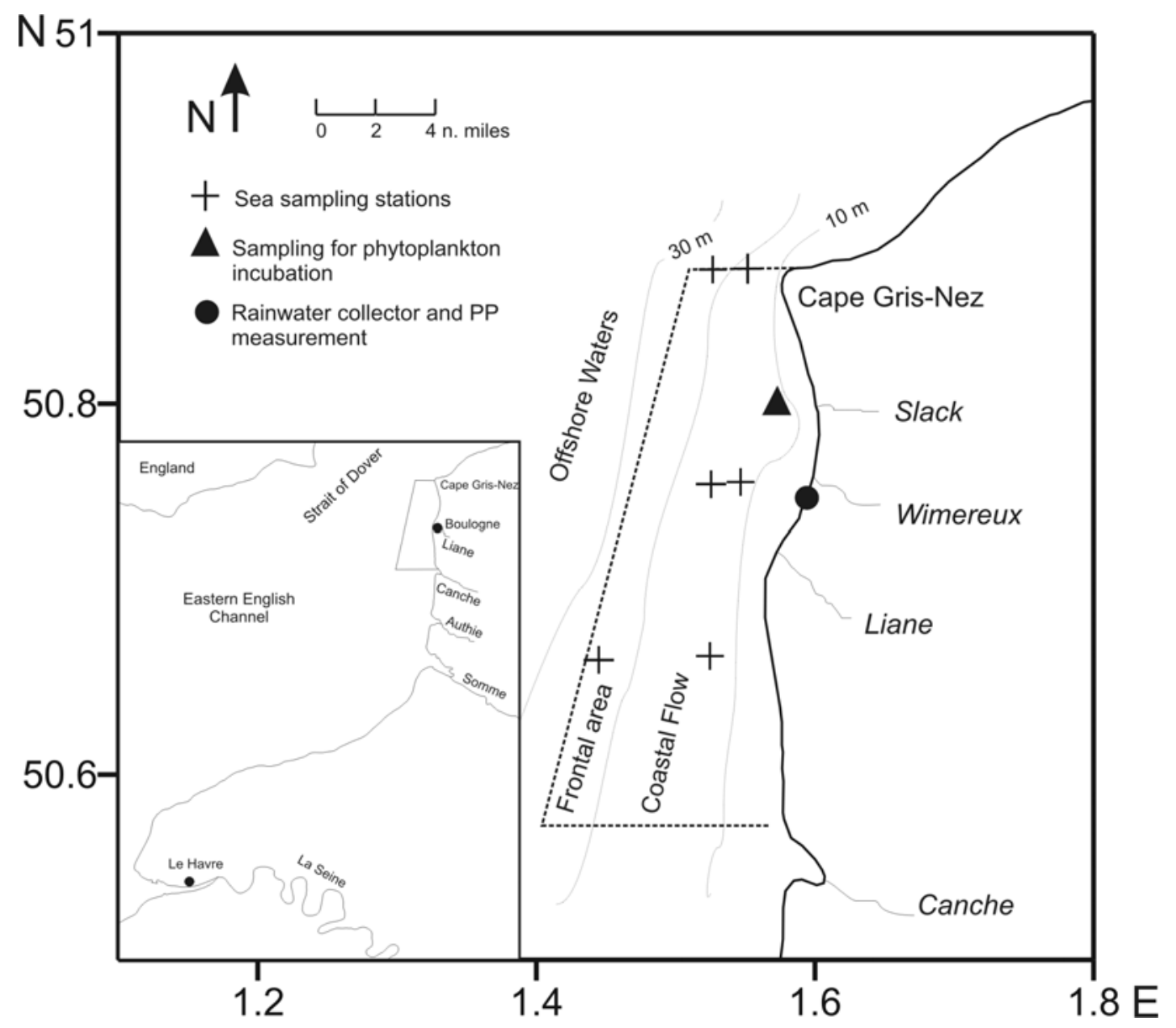

Figure 1: Study Site. Solid lines delimit the coastal box (CB) for stock calculations and comparison of atmospheric versus riverine inputs. Adapted from Seuront et al., 2002.
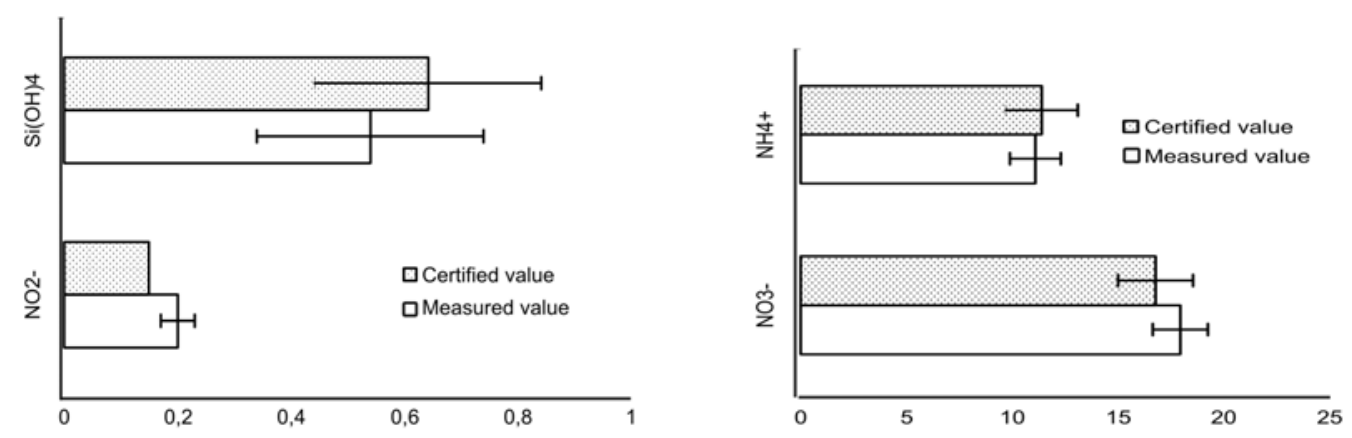

FIGURE 2

Figure 2: Precision and accuracy of the rainwater sampling and analysis method (all results in $\mu \mathrm{M}$ ). 

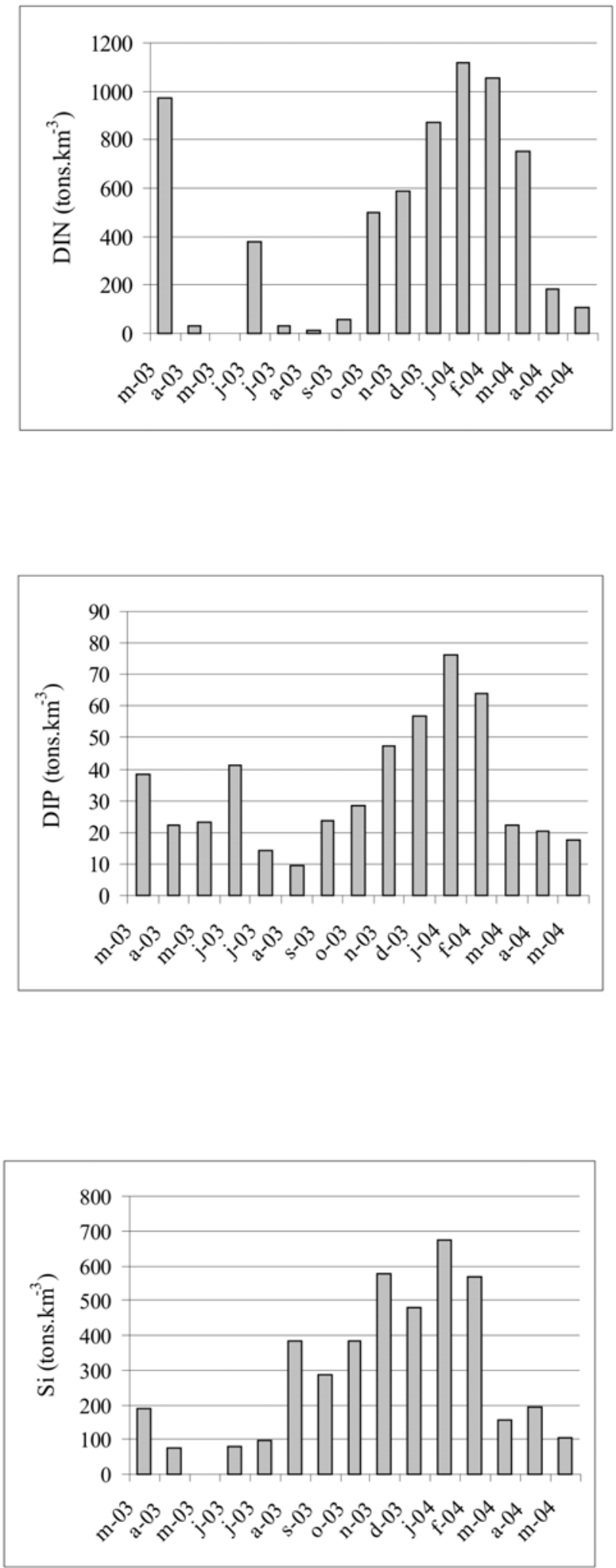

\section{FIGURE 3}

Figure 3: Evolution of DIN, DIP and Si concentrations for the CB "Strait of Dover", from March 2003 to March 2004 (T.km-3). 

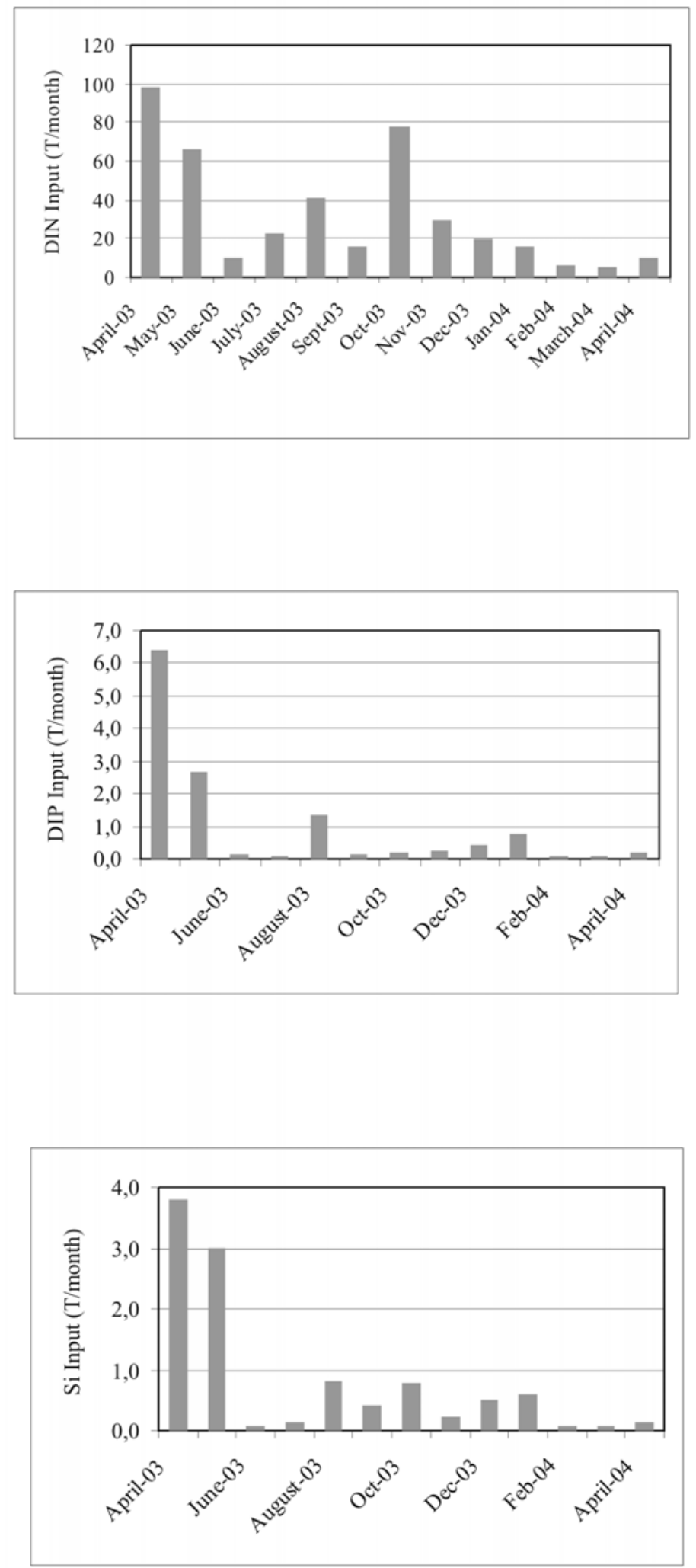

FIGURE 4

Figure 4: Evolution of wet atmospheric inputs of nutrients to the CB "Strait of Dover", from April 2003 to April 2004 (Tons.month-1). 


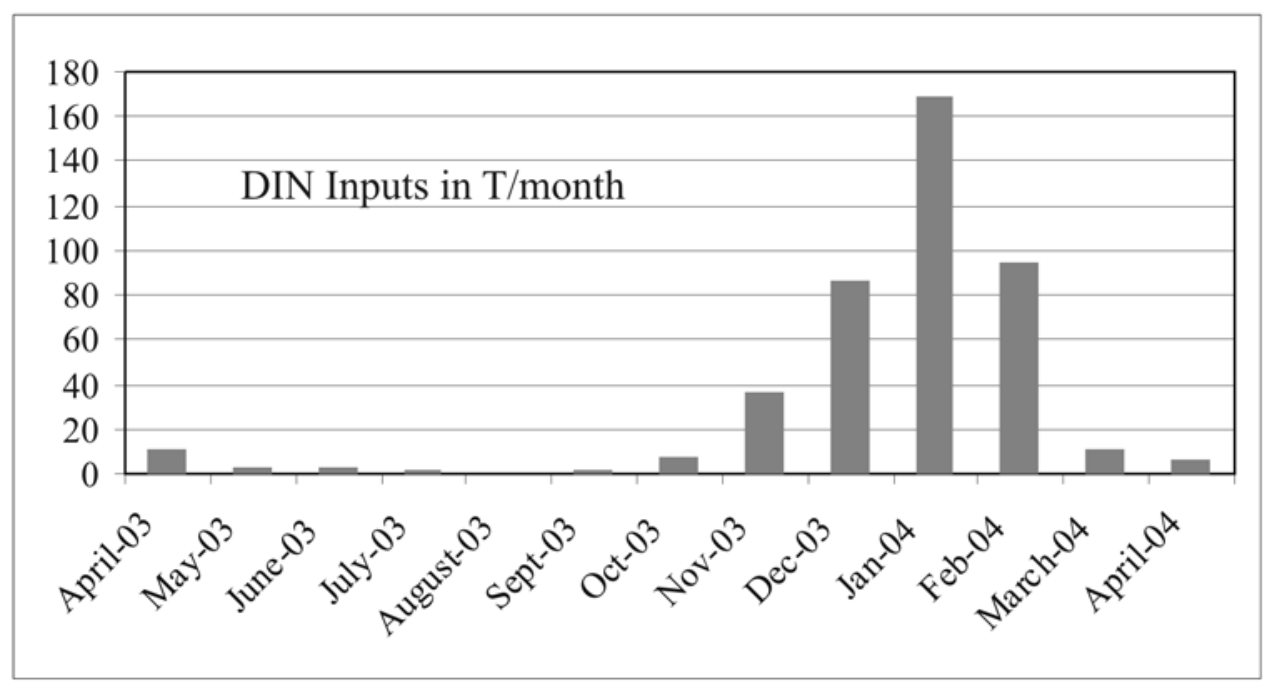

[a]

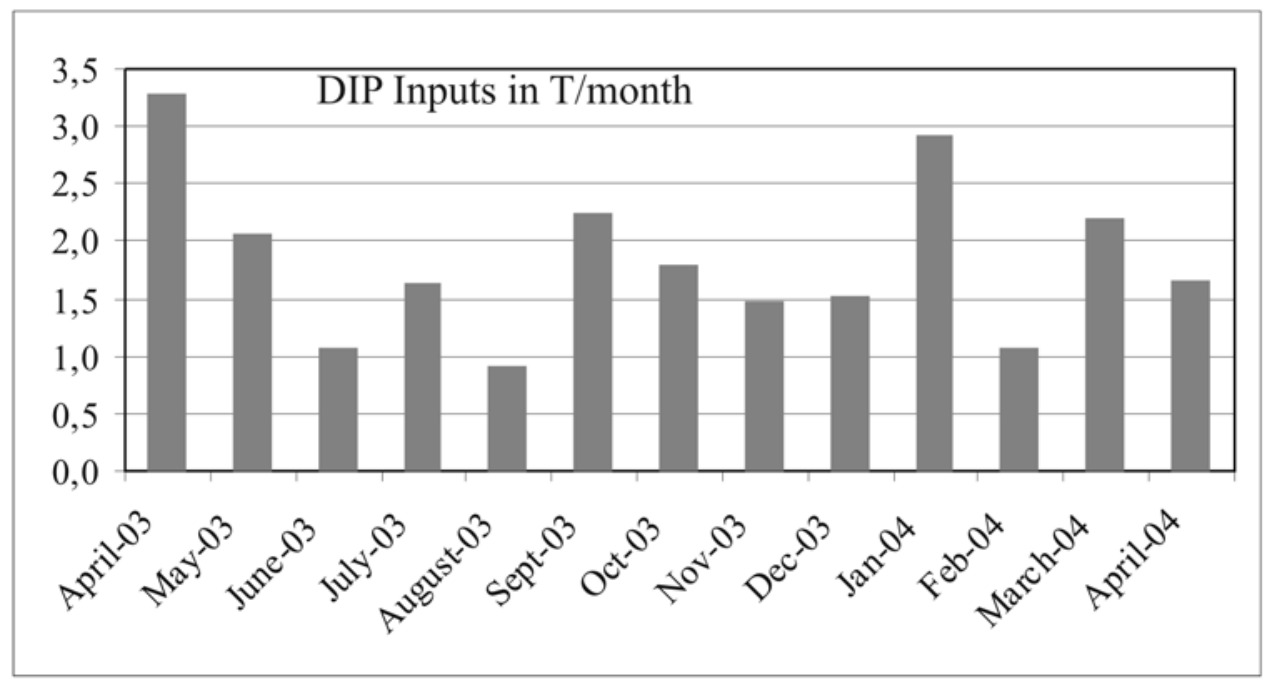

[b]

\section{FIGURE 5}

Figure 5: Net export of riverine nutrients to the CB "Strait of Dover" for DIN [a] and DIP [b], from April 2003 to April 2004 (Tons.month-1). 


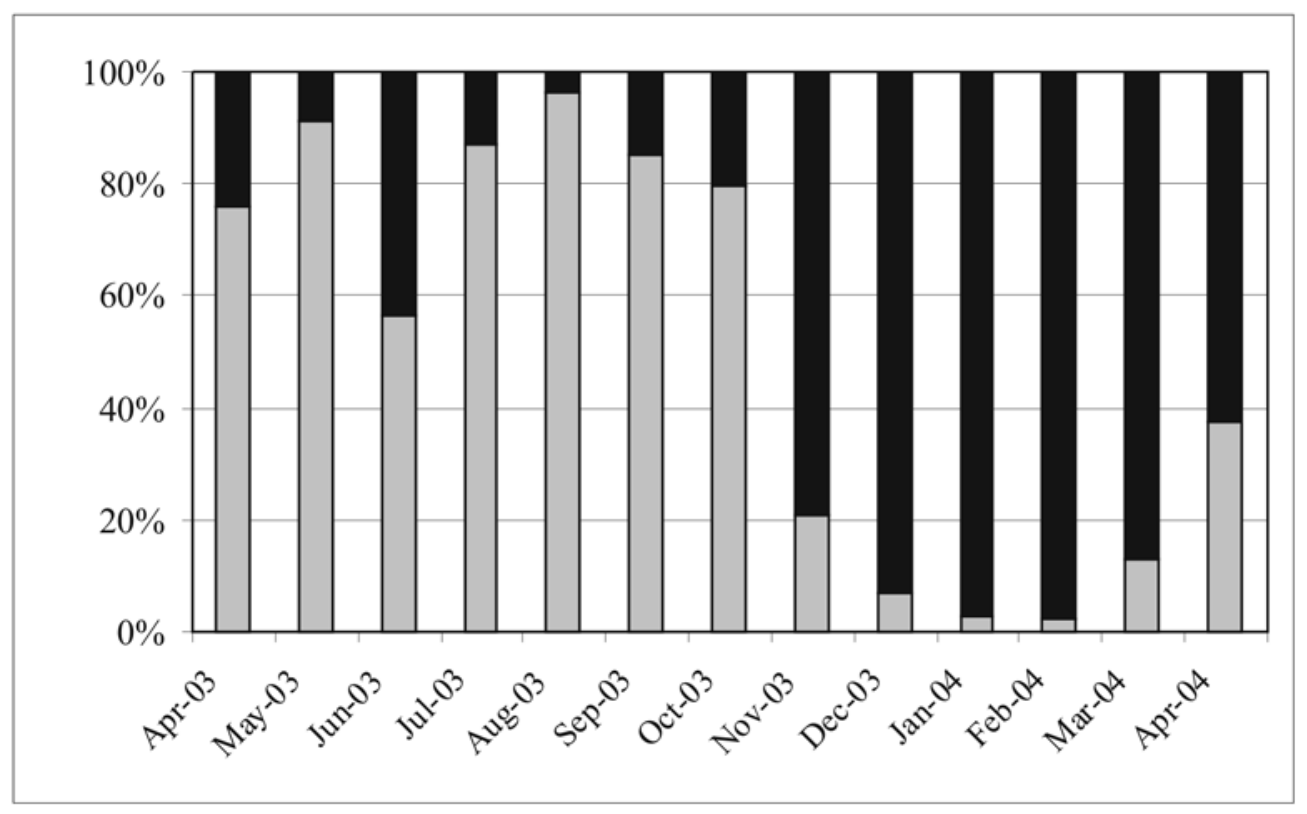

[a]

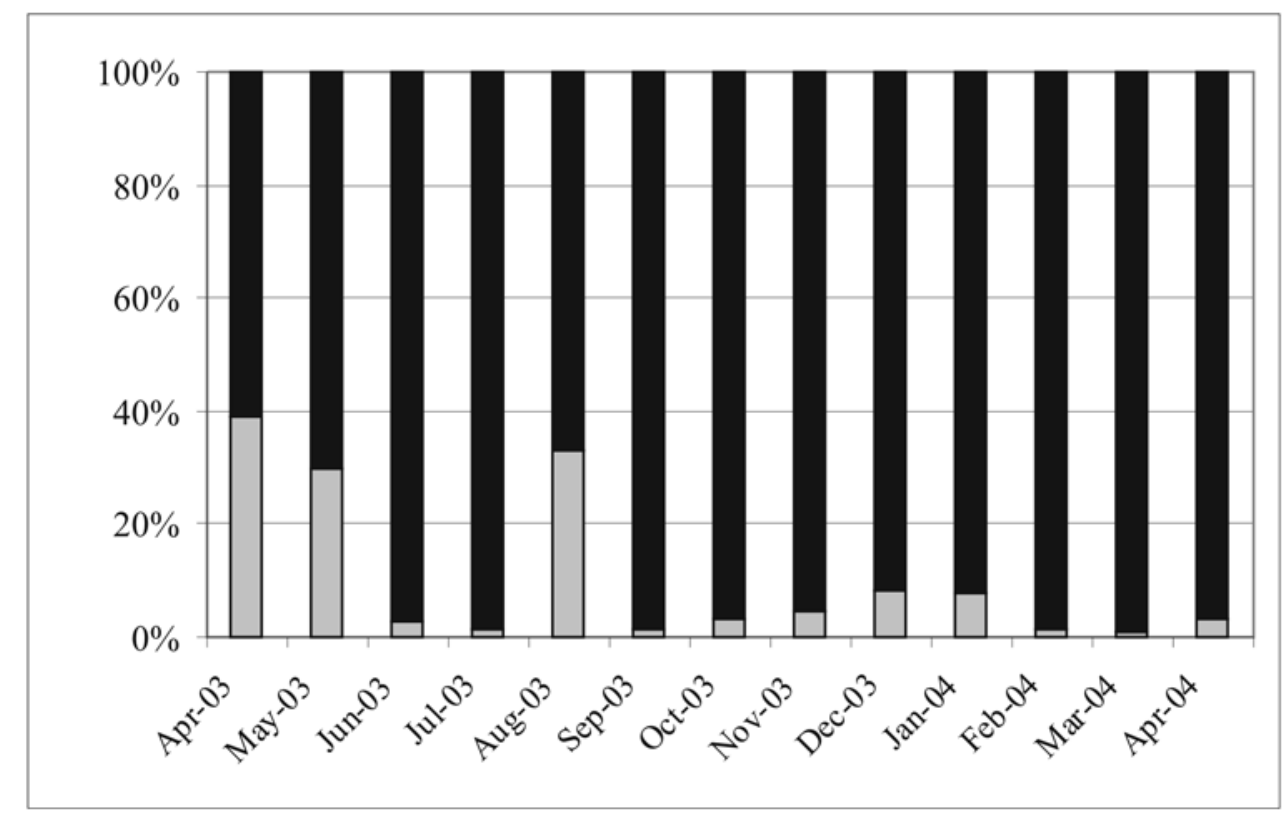

[b]

\section{FIGURE 6}

Figure 6: Comparison of nutrients inputs to the CB "Strait of Dover" for DIN [a] and DIP [b], from April 2003 to April 2004 (Black: Net riverine inputs; Grey: Wet atmospheric inputs). 